\title{
Erratum
}

Arch Pharm Res Vol 21, No 6, 753-758 1998

\section{Synthesis and Biological Evaluation of Novel 2-[Substituted acetyl]-amino-5-alkyl]-amino-5-alkyl-1,3,4-thiadiazoles}

\author{
Ashok K. Shakya ${ }^{1, *}$, Pradeep Mishra ${ }^{2}$, G. K. Patnaik, Rakesh Shukla and R. C. Srimal ${ }^{3}$ \\ ${ }^{1}$ Clinical Pharmacology \& Pharmacokinetics Ranbaxy Research Laboratories, PLOT 20, Sector 18, Udyog Vihar Gur- \\ goan (Haryana), India, '2Division of Medicinal Chemistry, Department of Pharmaceutical Sciences, Dr. Harisingh gour \\ Vishwavidyalaya [Formerly University of Saugor] Sagar 470003 (MP), India and Division of Pharmacology Central Drug \\ Research Institute, Lucknow 226001 (UP) India
}

The correct title is "Synthesis and Biological Evaluation of Novel 2-[Substituted acetyl]-amino-5alkyl-1,3,4-thiadiazoles". 